\title{
O EFEITO DA TEMPESTIVIDADE CONTÁBIL NO GERENCIAMENTO DE RESULTADOS DE EMPRESAS BRASILEIRAS LISTADAS NA B3
}

\author{
Nayara de Nazaré Brasil Salgado' \\ Paulo Vitor Souza de Souza²
}

Resumo

Objetivo: A tempestividade contábil consiste na disponibilidade da informação para os usuários a tempo de poder influenciá-los em suas decisões. O objetivo deste artigo consiste em verificar o efeito da tempestividade dos relatórios financeiros no gerenciamento de resultados de empresas brasileiras de capital aberto listadas na B3, utilizando três proxies para tempestividade: defasagem na publicação, perda do prazo da divulgação e a republicação.

Método: A amostra é constituída por 172 empresas, no período compreendido entre 2010 e 2018. A variável dependente representa o gerenciamento de resultados e foi mensurada pelo modelo de Jones Modificado por Dechow, Sloan e Sweeney (1995). A variável independente representa a tempestividade e variáveis de controle foram incluídas, sendo elas: tamanho da empresa, empresas auditadas por Big Four, endividamento, governança corporativa, fluxo de caixa operacional e prejuízo do período. Utilizou-se regressões com dados em painel.

Resultados: Os resultados fornecidos pelos seis modelos apontam que a tempestividade possui relação positiva e significativa com o gerenciamento de resultados, isto é, as empresas que demoram e, até mesmo, que perdem o prazo de publicação de seus relatórios financeiros sinalizam maior gerenciamento de resultados. Os achados também denotam que empresas que republicam, de maneira espontânea ou obrigatória, tendem a um maior gerenciamento de resultados.

Contribuições: Uma das principais contribuições da pesquisa consiste em evidenciar que a tempestividade dos relatórios financeiros pode sinalizar práticas oportunistas da gestão por meio do uso de gerenciamento de resultados, interferindo assim, no processo de tomada de decisões dos usuários da informação contábil.

Palavras-chave: Tempestividade; Gerenciamento de Resultados; Qualidade dos Lucros; Perda do Prazo de Divulgação.

' nayarabrasil49@gmail.com. Universidade Federal do Pará, Belém-PA. Brasil. https://orcid.org/0000-0003-4253-576X

2paulosouzx@gmail.com, Universidade Federal do Pará, Belém-PA. Brasil. https://orcid.org/0000-0001-5746-1746

- DOI: http://dx.doi.org/10.14392/asaa.2021140102

- Artigo submetido em: 01/10/2020. Aceito em: 07/12/2020. 
$\mathrm{P}$ ara auxiliar os usuários internos e externos, na decisão necessária a ser tomada, são utilizadas as informações provenientes dos relatórios financeiros. Desta forma, cada vez mais os usuários exigem que as demonstrações contábeis reportem informações de qualidade, isto é, que sejam úteis para suas decisões. O Comitê de Pronunciamentos Contábeis (CPC) (2019) afirma que a utilidade da informação consiste, fundamentalmente, na sua relevância e representação fidedigna e para melhorar as informações fornecidas, estas precisam ser comparáveis, verificáveis, compreensivas e tempestivas. No entanto, há fatores que podem influenciar, intencionalmente, na qualidade das informações devido à discricionariedade contábil dos gestores resultando na prática de gerenciamento de resultados em decorrência de caráter informacional ou do modo de agir oportunista (Subramanyam, 1996).

Para avaliar a qualidade da informação utiliza-se, normalmente, o lucro contábil em virtude do seu poder informacional de desempenho financeiro da empresa (Dechow, Ge \& Schrand, 2010) e capacidade de predição (Hendriksen \& Van Breda, 2012). Dentre tantas medidas utilizadas para verificar os efeitos causados na qualidade da informação contábil, Paulo (2007), a partir da análise de pesquisas anteriores, destaca três medidas: persistência; conservadorismo e gerenciamento de resultados.

Caracteriza-se o fenômeno do gerenciamento de resultados contábeis como uma ação deliberativa dos gestores de modificar, intencionalmente, os resultados contábeis em vista de alcançar benefícios particulares que não são os de expressar a realidade sobre o desempenho da empresa nem de promover a transparência das informações (Martinez, 2001; Schipper, 1989).

A representação fidedigna da informação é afetada pela prática de gerenciamento de resultados de maneira oportunista. Além disso, outra característica que torna a informação útil aos usuários é a relevância, sendo que, esta é melhorada pela tempestividade (CPC, 2019). A tempestividade consiste em possuir informações disponíveis no momento oportuno a ponto de influenciar nas escolhas dos usuários (CPC, 2019). A informação torna-se útil não somente por sua natureza ou pelo seu conteúdo, mas também está associada ao momento de anúncio das demonstrações contábeis, sendo assim, a qualidade da informação relaciona-se com a rapidez na divulgação aos seus usuários (Kirch, Lima \& Terra, 2012).

Considera-se a tempestividade da informação contábil como uma característica qualitativa relevante por ser capaz de influenciar na tomada de decisão dos seus usuários quando as informações são disponibilizadas no momento oportuno (Ahmad \& Kamarudin, 2003; Barcellos, Costa \& Laurence, 2014).

Quanto a temática da tempestividade, existem lacunas na literatura brasileira. Estudos anteriores delimitam-se nas investigações dos fatores que influenciam no momento de divulgação dos relatórios financeiros (Barcellos et al., 2014; Kirch et al., 2012; Sá, 2014; Souza, Silva \& Macedo, 2018).

Mediante o exposto, a presente pesquisa apresenta a seguinte questão-problema: Qual o efeito da tempestividade na publicação dos relatórios financeiros no gerenciamento de resultados de empresas brasileiras de capital aberto? Especificamente, o presente artigo tem como objetivo verificar o impacto das medidas de tempestividade da informação contábil no gerenciamento de resultados das empresas brasileiras de capital aberto listadas na B3.

A investigação do efeito da tempestividade na publicação dos relatórios na qualidade dos lucros implica na credibilidade das informações contábeis reportadas aos usuários sendo que esta caraterística tem o poder de influenciar na tomada de decisão. Torna-se relevante a pesquisa aos diversos usuários da informação contábil visto que promove a redução da assimetria informacional e, consequentemente, dos prejuízos causados pelo comportamento oportunista dos gestores. 
Ao órgão regulador do mercado, a pesquisa torna-se importante para auxiliar no bom e justo funcionamento do mercado financeiro para atração de novos investimentos e fomentar o crescimento da atividade econômica, indicado pelo aumento do Produto Interno Bruto (PIB) o qual reflete o desenvolvimento econômico do país, verificado pela geração de novos empregos e, consequentemente, o crescimento da oferta de produtos e serviços auxiliando no controle inflacionário.

Por fim, torna-se relevante a pesquisa por contribuir com a literatura brasileira por ampliar a ótica de investigação da tempestiviadade relacionando com outra proxy de qualidade da informação, anteriormente, limitada a investigação dos fatores para o momento de divulgação e também despertar nos discentes interesses para pesquisas posteriores e fomentar a importância de averiguar a qualidade de informação fornecida pelos profissionais contábeis.

Além da introdução, acrescentam-se mais quatro seções na estrutura deste estudo. A segunda seção refere-se ao embasamento teórico; a terceira seção aborda a metodologia; a quarta seção consiste na apresentação dos resultados da pesquisa; e por fim, a última seção apresenta as considerações finais, limitações e sugestões para as próximas pesquisas.

\section{REFERENCIAL TEÓRICO}

\subsection{Assimetria da informação e teoria da agência}

Com o desenvolvimento empresarial culminou-se num sistema organizacional mais complexo, sendo necessário a descentralização do controle de gestão, outrora, exclusivo aos proprietários (Nascimento \& Reginato, 2008). Neste contexto, surgiu a teoria da agência que apresenta como princípio fundamental as relações contratuais tanto formal como informal, ou seja, consiste numa relação principal-agente em que se presume que o agente executará algo pelo principal no qual se receberá remuneração (Martinez, 1998).

Considera-se que a relação entre o principal e o agente não se resume somente aos proprietários e gerentes, mas também entre gerentes, ou seja, a relação ocorre tanto de usuários externos com os administradores como também entre os usuários internos da informação (Nascimento \& Reginato, 2008). A teoria da agência busca alcançar eficiente modelo contratual, mas, com o desalinhamento de interesse entre o principal e agente, ocorre o problema de agência o qual decorre da necessidade de considerar que o agente também tem sua função utilidade própria em que consiste suas ações (Hendriksen \& Van Breda, 2012).

Considerando a função utilidade das partes envolvidas, Jensen e Meckling (1976, p. 5), afirmam que "se ambas as partes do relacionamento são maximizadoras de utilidade, existe boa razão para acreditar que o agente nem sempre agirá pelos melhores interesses do principal". A partir deste conflito de interesse, conforme, Nascimento e Reginato (2008), o fenômeno da assimetria informacional surge pelo conhecimento incompleto das informações necessárias para auxiliar nas escolhas dos usuários.

A assimetria da informação pode surgir por dois problemas: seleção adversa e risco moral. A primeira consiste em informação não disponibilizada de modo igualitário entre o principal e agente, isto é, há informações ocultas antes de ser efetivado o contrato e a segunda acontece quando o agente assume um comportamento oportunista ou fornece informações distorcidas para proveito próprio em que o principal não é capaz de monitorar as ações do agente por existir ações ocultas (Milgrom \& Roberts, 1992). 


\subsection{Qualidade dos lucros}

A importância do lucro contábil é devido ao seu poder informacional, por exemplo, a provável capacidade de predição (Hendriksen \& Van Breda, 2012). Sendo assim, torna-se necessário averiguar sua qualidade, determinando se as empresas reportam lucros com menor ou maior qualidade. Há fatores que podem afetar a qualidade como: conservadorismo, método de depreciação, lucro originário da operação da empresa e não de operações extraordinárias, influência da legislação fiscal, entre outros (Costa, Teixeira \& Nossa, 2002)

A qualidade dos resultados pode ser definida, conforme Dechow et al. (2010, p. 344), como "lucros de maior qualidade que fornecem mais informações sobre os recursos do desempenho financeiro de uma empresa e que são relevantes para uma decisão especifica tomada por um tomador de decisão especifico". A partir desta definição, consideram-se três características determinantes: (1) dependência da relevância da informação para a tomada de decisão; (2) lucros reportados são informativos de desempenho financeiro; e (3) combinação pela relevância do desempenho financeiro em detrimento da decisão e pela capacidade de mensuração do desempenho pelo sistema contábil.

Verifica-se que há uma quantidade de medidas que são possíveis de serem utilizadas para conferir os impactos causados na qualidade da informação contábil. Paulo (2007), a partir da análise de pesquisas anteriores, destaca três medidas: persistência; conservadorismo e gerenciamento de resultados. Nesta, presente pesquisa, optou-se por utilizar como proxy de qualidade dos lucros o gerenciamento de resultados, visto que, em decorrência da flexibilização da regulamentação e dos padrões contábeis, possibilita-se a subjetividade na adoção dos critérios e procedimentos contábeis por parte dos gestores a partir da necessidade de informação do usuário (Goulart, 2007).

Os gestores usam da subjetividade para intervir, intencionalmente, na elaboração dos relatórios financeiros a fim de manipulá-los para enganar os usuários da informação sobre o desempenho da empresa e poder influenciar os resultados contratuais que dependem do fornecimento das informações contábeis (Healy \& Wahlen,1999; Schipper, 1989).

Cabe salientar que além da prática do gerenciamento de resultados sob a ótica do lucro oportunista, é possível ocorrer também sob a ótica informacional em que se utiliza da discricionariedade contábil para melhorar a capacidade de lucro reportados em refletir o valor da empresa, isto é, melhorar a qualidade informacional (Schipper, 1989; Subramanyan, 1996).

Ressalta-se que para a investigação da existência da prática de gerenciamento de resultados pelos gestores é possível considerar os incentivos que podem influenciar a ação dos administradores, mediante teste dos padrões dos accruals não-esperados (accruals discricionários), verificando se esses são consistentes com aqueles incentivos (Healy \& Wahlen, 1999).

Dentre os vários incentivos relacionados com as práticas de gerenciamento de resultados, Martinez (2001) destaca quatro classificações: motivações vinculadas ao mercado de capitais; motivações contratuais; motivações regulamentares e custos políticos. Martinez (2013), destaca duas formas da prática de gerenciamento de resultados: por accruals e por decisões operacionais.O primeiro consiste nas escolhas de práticas contábeis permitidas pela legislação e o segundo pelas tomadas de decisões operacionais com a finalidade de produzir relatórios e divulgação dos números contábeis divergentes (Martinez \& Cardoso, 2009).

Considera-se que a mensuração dos níveis de accruals discricionários por uma empresa pode segregar, comparativamente, em empresas que gerenciam mais ou menos seus resultados, visto que, pela 
métrica de mensuração, todas as empresas, em determinado momento, gerenciariam seus resultados (Martinez, 2013).

Normalmente, estima-se como proxy de gerenciamento de resultados os accruals discricionários. Nas pesquisas brasileiras, Baptista (2009) verificou que as proxies mais utilizadas para o gerenciamento de resultados foram: o intervalo de pequenos lucros da distribuição de frequência de resultados, o"erro" dos modelos de estimação de accruals não-discricionárias agregadas (ou seja, accruals discricionários) e o "erro" dos modelos de estimação de accruals não-discricionários específicos.

\subsection{Tempestividade da informação contábil}

De acordo com o Pronunciamento Conceitual Básico 00 (R2) (CPC, 2019), a informação contábil financeira para ser útil, precisa ser relevante e representar de forma fidedigna, estas características qualitativas são as fundamentais. Para melhorar a utilidade da informação é preciso ser comparável, verificável, tempestiva e compreensível.

Considera-se a tempestividade da informação contábil como uma característica qualitativa relevante por ser capaz de influenciar na tomada de decisão dos seus usuários quando as informações são disponibilizadas no momento oportuno (Ahmad \& Kamarudin, 2003; Barcellos, Costa \& Laurence, 2014).

Tornar a informação útil não está, necessariamente, relacionada somente com a natureza e com o conteúdo, mas também com o período de sua divulgação, isto é, a tempestividade. Quanto a determinação do momento de anúncio, o fornecimento de informações de alto nível de qualidade e confiabilidade podem perder sua utilidade se não forem divulgadas no momento oportuno. Sendo assim, a qualidade da divulgação está associada também a rapidez com que estes relatórios são disponibilizados aos usuários (Kirch et al., 2012).

A discricionariedade do gestor, quanto a determinação do momento de divulgação como também da definição de práticas contábeis dentro dos limites da legislação societária, possibilita a prática do gerenciamento dos resultados por accruals. Conforme Cupertino (2013), no período entre encerramento do exercício social e o momento de publicação dos relatórios financeiros, os gestores verificam os resultados operacionais e determinam o montante a ser registrado mediante gerenciamento por accruals, isto é, são uma forma ex post de manipulação.

A determinação do momento adequado para divulgação dos relatórios financeiros consiste na defasagem na publicação, que é o período de tempo entre a data de encerramento do exercício social e a data de divulgação (Kirch et al., 2012). Quanto ao momento de divulgação dos relatórios, é passível de ação oportunista, pois, conforme a teoria positiva contábil, a escolha é determinada por incentivos existentes para tardar como para antecipar a divulgação (Barcellos et al., 2014; Martinez, 2013).

Para garantir acessibilidade às informações contábeis, a Lei das Sociedades por ações estabelece, de forma indireta, um limite para a divulgação dos relatórios financeiros de três meses após o término do exercício social quando discorre sobre a realização da Assembleia Geral Ordinária (Lei n. 6404, 1976).

Há um melhoramento na tomada de decisão dos usuários e, consequentemente, a redução da assimetria informacional no mercado de capitais mediante anúncio tempestivo das informações (Owusu-Ansah \& Leventis, 2006). Supõem-se que as empresas que tendem a perder o prazo de divulgação das informações fornecem informações intempestivas, sendo assim, a demora na divulgação dos relatórios maximiza a incerteza para as decisões de investimentos e diminui o conteúdo e relevância da informação (Turel, 2010). 
Ocorre também a necessidade de republicação das demonstrações tanto obrigatória como espontâneas. As primeiras são exigidas pelo órgão regulador (CVM) ou partes interessadas (auditores independentes), enquanto que as segundas são realizadas por iniciativa da empresa e não correlacionada com a determinação contratual ou normativa (Marques, 2016).

Segundo Marques (2016), a republicação das demonstrações contábeis consiste na necessidade de correção de erros e/ou omissões no que se refere ao reconhecimento, mensuração ou divulgação das informações o que, significativamente, interfere no processo avaliativo e decisório dos usuários externos, possibilitando, portanto, a redução do risco da seleção adversa proveniente da assimetria informacional. Tal alteração origina-se a partir da escolha intencional de política contábeis que sejam favoráveis aos interesses específicos dos gestores, ou, até mesmo, pela solicitação da retificação das informações divulgadas quando identificados erros ou fraudes.

Considera-se que a republicação, sendo ela intencional ou não, decorrente de erros e/ou omissões, afeta a qualidade da informação reportada, pois representa indicativo de existência de manipulação intencional dos resultados no qual afetaria a tomada de decisão dos usuários da informação (Dechow et al., 2010; Di Pietra, Mcleay \& Ronen, 2014).

\subsection{Delineamento das hipóteses de pesquisa}

A primeira hipótese de pesquisa refere-se a defasagem na publicação. Espera-se que as empresas que tem um maior prazo de divulgação tende a um maior gerenciamento de resultados. Vários estudos afirmam que empresas que apresentaram resultado negativo tendem a divulgar em um prazo maior comparado com as empresas que apresentaram lucro (Barcellos et al., 2014; Kirch et al., 2012; Paulo \& Leme, 2009; Sá, 2014; Silva, Silva \& Sancovschi, 2006). Como também se destaca, dentre vários incentivos para manipulação oportunista dos resultados, que evitar a divulgação de perdas contábeis, isto é, prejuízos, representam baixa qualidade de informação (Paulo, 2007). Desta forma, a primeira hipótese de pesquisa é descrita a seguir:

$\mathrm{H} 1$ : Empresas que demoram a divulgar seus relatórios financeiros tendem a um maior gerenciamento de resultados reportando lucros de menor qualidade.

A segunda hipótese de pesquisa corresponde a perda do prazo de divulgação. Souza et al. (2018) apontam que empresas auditadas pela Big Four apresentam menor possibilidade de perder o prazo de divulgação enquanto que as empresas endividadas e com prejuízo tem alta possibilidade de perder o prazo de divulgação. Observa-se que a presença de auditores independentes de empresas do grupo Big Four nas entidades auditadas resulta em menor propensão de gerenciamento de resultados por escolhas contábeis (através dos accruals discricionários) em relação as não pertencentes ao grupo (Almeida \& Almeida, 2009; Martinez, 2011; Martinez, 2013). Como também, considera-se que, entre os incentivos de gerenciamento, o nível de endividamento sinaliza baixa qualidade dos lucros (Dechow et al., 2010; Martinez, 2001). Com base nesta associação de fatores que influenciam na perda do prazo ou não como aqueles relacionados aos incentivos e contra incentivos, surge a seguir a segunda hipótese desta pesquisa:

H2: Empresas que perdem o prazo para a divulgação dos relatórios financeiros tendem a um maior gerenciamento de resultados reportando lucros de menor qualidade.

A terceira hipótese de pesquisa está associada a republicação dos relatórios financeiros. Marques, Amaral, Souza, Santos e Belo (2017), apresentaram que os incentivos de gerenciamento de resultados referente aos custos políticos (medido pelo tamanho da firma) e ao oportunismo do agente (medido 
pelo pacote de remuneração) tem efeito positivamente significativo sobre a republicação, quanto ao nível de endividamento apresentou resultados esperados, porém, não apresentou suporte estatísticos significativos. As republicações representam um indicativo de gerenciamento de resultados (Dechow et al., 2010). Sendo assim, a terceira hipótese desta pesquisa pode ser apresentada conforme segue:

H3: Empresas que republicam os seus relatórios financeiros tendem a um maior gerenciamento de resultados reportando lucros de menor qualidade

\section{METODOLOGIA}

\subsection{Definição da amostra e coleta de dados}

A pesquisa tem como finalidade analisar se a tempestividade na publicação dos relatórios financeiros tem impacto na qualidade dos lucros mediante gerenciamento de resultados. Sendo assim, foram analisadas, inicialmente, o total de 301 empresas listadas no Brasil Bolsa Balcão (B3), entre o período de 2010 a 2018.

A Tabela 1 demonstra a quantidade de empresas que compõem a amostra, partindo da quantidade inicial do estudo e os critérios utilizados para exclusão de empresas nesta amostra:

Tabela 1 - Critérios para exclusão de empresas da amostra
\begin{tabular}{|l|c|}
\hline Observações de empresas entre o período de 2010 a 2018 & 301 \\
\hline (-) Empresas que não se repetem entre os anos de analise & $(85)$ \\
\hline (-) Empresas que pertencem ao setor financeiro & $(44)$ \\
\hline (=) número final de empresas contidas na pesquisa & 172 \\
\hline \multicolumn{2}{|c|}{ Fonte: Elaborado pelos autores (2020). }
\end{tabular}

De acordo com a definição dos critérios utilizados para exclusão da amostra desta pesquisa totalizou-se, no período de 2010 a 2018, a utilização de 172 empresas para cada ano de análise, correspondente a 1548 observações neste período de análise.

Cabe ressaltar que as informações econômico-financeiras foram obtidas mediante a base de dados da ComDinheiro e tabuladas em planilhas Excel, as quais servem de base para o sistema estatístico utilizado para obtenção dos resultados.

3.2 Modelo de gerenciamento de resultados

Para a presente pesquisa utilizou-se os accruals discricionários como proxy de gerenciamento de resultados visto que os accruals podem ser usados pelos gestores como instrumento de alcance de seus próprios interesses (Paulo, 2007). Para mensuração dos accruals discricionários, desta pesquisa, elegeu-se a utilização do modelo de Jones Modificado por Dechow et al. (1995). A seguir, de forma sistemática, serão descritos os dois momentos necessários para a mensuração dos accruals discricionários.

Primeiramente, descobrir os accruals totais (TA) da empresa, no qual é, comumente, feita com enfoque no balanço patrimonial (Martinez, 2013) conforme a Equação 1 a seguir:

$$
\mathrm{TA}_{\mathrm{it}}=\left(\Delta \mathrm{CA}_{\mathrm{it}}-\Delta \mathrm{CL}_{\mathrm{it}}-\Delta \mathrm{Cash}_{\mathrm{it}}+\Delta \mathrm{STD}_{\mathrm{it}}-\mathrm{Dep}_{\mathrm{it}}\right) / \mathrm{At}_{\mathrm{it}-\mathrm{1}}(1)
$$


Para o segundo momento é necessário encontrar as estimativas dos parâmetros $\alpha, \beta 1$ e $\beta 2$ e os accruals discricionários (DA) mediante o modelo de Jones Modificado conforme a Equação 2 a seguir:

$$
T A_{i t}=a\left(1 / A_{t-1}\right)+\beta_{1}\left(\Delta R_{i t}-\Delta C R_{i t}\right)+\beta_{2}\left(P P E_{i t}\right)+\mu_{i t}(2)
$$

Ressalta-se que, para esta pesquisa, os accruals discricionários foram obtidos por meio dos resíduos $\left(\mu_{\mathrm{i}, \mathrm{t}}\right)$ da regressão da Equação 2 e utilizados nos modelos de regressão.

Para melhor compreensão das equações descritas, anteriormente, na Tabela 2, serão elencados os significados das abreviaturas e símbolos utilizados.

Tabela 2 - Abreviaturas, símbolos e significados das variáveis do modelo de gerenciamento

\begin{tabular}{|c|c|}
\hline Abreviaturas & Significado \\
\hline $\mathrm{TA}_{\mathrm{i}, \mathrm{t}}$ & Accruals totais da empresa i no período $t$, ponderados pelos ativos totais em $\mathrm{t}-1$ \\
\hline$\Delta C \mathrm{~A}_{\mathrm{i}, \mathrm{t}}$ & Variação nos ativos circulantes da empresa i no período $t$ \\
\hline$\Delta \mathrm{CL}_{\mathrm{i}, \mathrm{t}}$ & Variação nos passivos circulantes da empresa i no período $t$ \\
\hline$\Delta$ Cash $_{\mathrm{i}, \mathrm{t}}$ & Variação de caixa e equivalente de caixa da empresa i no período $t$ \\
\hline$\Delta \mathrm{STD}_{\mathrm{i}, \mathrm{t}}$ & Variação da dívida do passivo circulante da empresa i no período $t$ \\
\hline $\mathrm{Dep}_{\mathrm{i}, \mathrm{t}}$ & Despesa com depreciação e amortização da empresa i no período t \\
\hline $\mathrm{AT}_{\mathrm{i}, \mathrm{t}-\mathrm{I}}$ & Ativos Totais da empresa i no final do período $\mathrm{t}-1$ \\
\hline$\Delta \mathrm{R}_{\mathrm{it}}$ & $\begin{array}{l}\text { Variação das receitas líquidas da empresa i no período } t-1 \text { para o período } t \text {, ponderada pelos ativos totais no } \\
\text { final do período } t-1\end{array}$ \\
\hline$\Delta \mathrm{CR}_{\mathrm{it}}$ & $\begin{array}{l}\text { Variação das contas a receber (clientes) da empresa i no período } \mathrm{t}-1 \text { para o período } \mathrm{t} \text {, ponderada pelos ativos } \\
\text { totais no final do período } \mathrm{t}-1\end{array}$ \\
\hline $\mathrm{PPE}_{\text {it }}$ & $\begin{array}{l}\text { Saldos das contas de ativo imobilizado da empresa i no final do período } t \text {, ponderados pelos ativos totais no } \\
\text { final do período } t-1\end{array}$ \\
\hline$\mu_{\mathrm{i}, \mathrm{t}}$ & erro da regressão (resíduos) que representa a parte discricionária dos accruals \\
\hline$a, \beta 1, \beta 2$ & Coeficientes estimados nas regressões da Equação 2 \\
\hline
\end{tabular}

Fonte: Elaborado pelos autores (2020)

\subsection{Definição das variáveis de estudo}

O Gerenciamento de Resultado (GR) foi definido como a variável de interesse da pesquisa na qual será mensurada mediante o modelo de Jones Modificado por Dechow et al. (1995), o qual fornece a mensuração dos accruals discricionários das empresas.

Para averiguação da variável dependente, nesta pesquisa, foram testadas três variáveis independentes que representam proxies de tempestividade na publicação dos relatórios financeiros das companhias, sendo elas: a perda de prazo de divulgação de relatórios financeiros; defasagem da divulgação e republicação (Kirch et al., 2012; Marques et al., 2017; Souza et al., 2018).

Além disso, foram utilizadas variáveis que visam controlar a variação dos accruals das entidades, sendo elas: Tamanho (TAM); Empresas Auditadas pela Big Four (AUD); Endividamento (END); Níveis Diferenciados de Governança Corporativa (GOV); empresas com Prejuízo (PREJ) e o Fluxo Operacional de Caixa (FCO). A Tabela 3 oferece as variáveis da pesquisa e como estas foram mensuradas. 
Tabela 3 - Variáveis, forma de mensuração e fonte dos dados

\begin{tabular}{|c|c|c|}
\hline Variáveis & Forma de mensuração & Fonte de Dados \\
\hline \multicolumn{3}{|c|}{ Variável Dependente } \\
\hline Gerenciamento de Resultados (ADD) & $\begin{array}{l}\text { Módulo dos accruals discricionários da empresa i no período t pelo } \\
\text { Modelo de Jones Modificado por Dechow et al. (1995). }\end{array}$ & Site ComDinheiro \\
\hline \multicolumn{3}{|c|}{ Variáveis Independentes } \\
\hline Defasagem na Publicação (DP) & Defasagem na divulgação em número de dias (Kirch et al., 2012). & Relatórios da CVM \\
\hline Perda do Prazo (PD, & $\begin{array}{l}\text { Dummy que assume } 1 \text { se a companhia perdeu o prazo de divulgação, } 0 \\
\text { caso contrário (Souza et al., 2018). }\end{array}$ & Relatórios da CVM \\
\hline Republicação (REP) & $\begin{array}{l}\text { Dummy que assume } 1 \text { se a companhia republicou suas demonstrações, } \\
0 \text { caso contrário (Marques et al, 2017). }\end{array}$ & Relatórios da CVM \\
\hline \multicolumn{3}{|c|}{ Variáveis de Controle } \\
\hline Tamanho (TAM) & LN(Ativos), onde LN = logaritmo natural. (Kirch et al., 2012) & Site ComDinheiro \\
\hline Auditoria (AUD) & $\begin{array}{l}\text { Dummy que assume } 1 \text { se a companhia é auditada por Big Four, } 0 \text { caso } \\
\text { contrário (Ahmad \& Kamarudin, 2003). }\end{array}$ & Relatórios da CVM \\
\hline Endividamento (END) & Passivo Total/Ativo Total (Sá, 2014). & Site ComDinheiro \\
\hline Governança Corporativa (GOV) & $\begin{array}{l}\text { Dummy assume } 1 \text { se a companhia aderiu ao Nível 1, Nível } 2 \text { ou ao Novo } \\
\text { Mercado da B3, } 0 \text { caso contrário (Kirch et al., 2012) }\end{array}$ & Site ComDinheiro \\
\hline Prejuízo (PREJ) & $\begin{array}{c}\text { Dummy que assume } 1 \text { se a companhia apresentou prejuízo líquido no } \\
\text { trimestre, e } 0 \text { caso contrário (Kirch et al., 2012) }\end{array}$ & Site ComDinheiro \\
\hline Fluxo de Caixa Operacional (FCO) & $\begin{array}{l}\text { Logaritmo do Fluxo de caixa operacional (Moreira, Jones, Tavares, Ferh, } \\
\qquad \& \text { Silva, 2014) }\end{array}$ & Site ComDinheiro \\
\hline
\end{tabular}

Fonte: Elaborado pelos autores (2020).

Ressalta-se que após a adesão das proxies de tempestividade mediante análise de pesquisas anteriores sobre esta temática foram construídas hipóteses $(\mathrm{H} 1, \mathrm{H} 2$ e H3) a serem testadas que estão descritas na subseção 2.4 deste trabalho.

\subsection{Modelos utilizados no estudo}

Para o exame dos dados deste presente estudo elegeu-se a utilização do modelo estatístico de regressão por meio de dados em painéis, tanto por efeitos fixos quanto por aleatórios, para a verificação da relação existente entre as variáveis apresentadas na Tabela 3. A Equação 3 apresentada a seguir demonstra o modelo geral da proposta da equação para regressão com dados em painéis do qual foi desmembrada em modelos específicos.

$$
\left|A D D_{i, t}\right|=\beta_{0}+\beta_{1} \operatorname{TEMP}_{\mathrm{i}, \mathrm{t}}+\beta_{2} \operatorname{TAM}_{\mathrm{i}, \mathrm{t}}+\beta_{3} \mathrm{END}_{\mathrm{i}, \mathrm{t}}+\beta_{4} \mathrm{AUD}_{\mathrm{i}, \mathrm{t}}+\beta_{5} \mathrm{GOV}_{\mathrm{i}, \mathrm{t}}+\beta_{6} \mathrm{PREJ}_{\mathrm{i}, \mathrm{t}}+\beta_{7} \mathrm{FCO}_{\mathrm{i}, \mathrm{t}}+\varepsilon_{\mathrm{i}, \mathrm{t}} \text { (3) }
$$

A variável dependente denominada como ADD refere-se aos accruals discricionários obtidos por meio do modelo de gerenciamento de resultado de Dechow et al. (1995), cujo modo de mensuração foi descrito na subseção 3.2 desta pesquisa. Após a igualdade da equação é apresentada a variável independente e variáveis de controle como descritos na Tabela 3 e $\varepsilon_{\mathrm{i}, \mathrm{t}}$ refere-se ao termo de erro do modelo estimado.

A nível de obtenção de resultados da variável independente foram estimadas regressões para cada proxy de tempestividade (TEMP) utilizada neste trabalho. A seguir serão demonstradas as equações correspondentes aos modelos de regressão utilizados.

Primeiramente, para a proxy defasagem na publicação $(\mathrm{H} 1)$ foram estimados dois modelos de regressões referente a quantidade de dias utilizados pela empresa para divulgação da primeira versão das demonstrações (DP1) e para última versão divulgada (DP2), os quais corresponderam aos Modelos 1 e 2 desta pesquisa. 


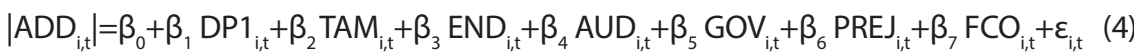

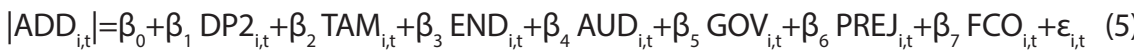

No segundo momento, da mesma forma, aconteceu para a proxy perda do prazo $(\mathrm{H} 2)$ no qual foram estimadas regressões referentes a empresas que perderam o prazo de divulgação das DFP, das ITR, separadamente, e por último, em conjunto a DFP e ITR, os quais corresponderam aos Modelos 3, 4 e 5 desta pesquisa.

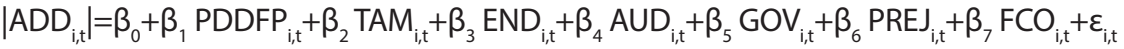

$$
\begin{aligned}
& \left|A D D_{i, t}\right|=\beta_{0}+\beta_{1} \text { PDITR }_{i, t}+\beta_{2} \text { TAM }_{i, t}+\beta_{3} \text { END }_{i, t}+\beta_{4} \text { AUD }_{i, t}+\beta_{5} \text { GOV }_{i, t}+\beta_{6} \text { PREJ }_{i, t}+\beta_{7} \text { FCO }_{i, t}+\varepsilon_{i, t} \\
& \left.\left|A D_{i, t}\right|=\beta_{0}+\beta_{1} \text { PDDFPITR }_{i, t}+\beta_{2} \text { TAM }_{i, t}+\beta_{3} \text { END }_{i, t}+\beta_{4} \text { AUD }_{i, t}+\beta_{5} G_{i, t}+\beta_{6} \text { PREJ }_{i, t}+\beta_{7} \text { FCO }_{i, t}\right)+\varepsilon_{i, t} \text { (8) }
\end{aligned}
$$

Finalmente, o Modelo 6 corresponde a estimação da regressão referente as empresas que republicaram (H3) suas demonstrações seja pela exigência da CVM, como por iniciativa da própria empresa, conforme demostrado a seguir:

$$
\left|A D D_{i, t}\right|=\beta_{0}+\beta_{1} \operatorname{REP}_{i, t}+\beta_{2} \operatorname{TAM}_{\mathrm{i}, \mathrm{t}}+\beta_{3} \mathrm{END}_{\mathrm{i}, \mathrm{t}}+\beta_{4} A U D_{i, \mathrm{t}}+\beta_{5} \mathrm{GOV}_{\mathrm{i}, \mathrm{t}}+\beta_{6} \operatorname{PREJ}_{\mathrm{i}, \mathrm{t}}+\beta_{7} \mathrm{FCO}_{\mathrm{i}, \mathrm{t}}+\varepsilon_{\mathrm{i}, \mathrm{t}}
$$

Os resultados das regressões descritas acima e de testes adicionais, foram fornecidos por meio da utilização do software estatístico: Gnu Regression, Econometrics and Time- series Library (GRETL).

\section{RESULTADOS E DISCUSSÕES}

\subsection{Testes de validação do modelo de regressão}

Esta subseção abordará os resultados obtidos por meio da estimação dos seis modelos de regressão com dados em painel para as proxies de tempestividade utilizadas nesta pesquisa. Tornou-se necessária a verificação dos comportamentos dos dados desta pesquisa por meio da aplicação de testes de validação dos modelos de regressão utilizados.

Os testes aplicados para cada modelo foram: (1) heterocedasticidade dos resíduos por meio do teste de White; (2) teste de normalidade; e (3) teste de multicolinearidade por meio de Fatores de Inflação da Variância (FIV).

Como também para a escolha do tipo de efeito utilizado para as interações dos dados nas regressões em painel, foram realizados os testes de diagnóstico de painel. Sendo eles: (1) teste de variância dos resíduos; (2) teste de Breusch-Pagan e, por fim, (3) teste de Hausman.

Quanto ao fenômeno da heterocedasticidade, os resíduos da regressão dos seis modelos utilizados apresentaram o resultado do LM entre 209,86 e 224,508 e do Qui-quadrado (2) entre 279,245 e 293,567, como também, o $\mathrm{p}$ - valor $<0,05$ indicando que os resíduos são heterocedásticos, por isso, foram necessário a utilização do teste de White para correção dos erros-padrão robustos por meio da matriz HAC.

Quanto ao teste de normalidade dos resíduos das regressões obteve o resultado de que os seis modelos rejeitam hipótese nula de distribuição normal dos resíduos, pois apresentaram um p- valor <0,05. Todavia, considerando que para esta pesquisa a quantidade de observações dos modelos foram de 1548, pode-se assim, considerar que os resíduos possuem normalidade em sua distribuição.

Quanto aos resultados obtidos no teste de multicolinearidade por meio da FIV para os modelos, verificou-se que as variáveis não são multicolineares, pois todos os modelos apresentam a FIV abaixo 
de 10,00, no intervalo de 1,014 e 1,823, que indicam que as variáveis não apresentam o problema de multicolinearidade, isto é, nenhuma das variáveis independentes possuem correlação entre si.

Com o intuito de encontrar o efeito de painel mais adequado para os dados utilizados nesta pesquisa aplicou-se os testes de diagnóstico em painel. Pelo teste de variância dos resíduos, todos os modelos validam a hipótese alternativa de efeitos fixos, em desfavor de MQO agrupado. No teste de Breusch-Pagan, todos os modelos validam a hipótese alternativa de efeitos aleatórios, ao invés de MQO agrupado. E, por fim, pelo teste de Hausman, todos os modelos validam a hipótese alternativa de efeitos fixos ao invés de efeitos aleatórios. Todos os Modelos utilizados nesta pesquisa adotaram o modelo de efeito fixo, exceto, nos Modelos 2 e 5.

Para a presente pesquisa, optou-se nos Modelos 2 e 5 pela utilização de efeitos aleatórios nas regressões com dados em painel, em virtude do fornecimento de resultados mais robustos e, consequentemente, mais consistentes.

Cabe ressaltar que para os modelos que utilizaram o modelo de efeito fixo de painel, a variável correspondente ao nível diferenciado de governança corporativa foi, automaticamente, omitida no momento da execução do software estatístico, Gretl, visto que aquela apresentava no decorrer dos anos da amostra os mesmos valores, ou seja, apresentava problema de colinearidade exata, isto é, a existência de relação entre as variáveis independentes. Com isso, somente nos Modelos 2 e 5, com utilização do modelo de efeitos aleatórios, apresentam resultados relacionados a esta variável.

\subsection{Testes de regressão com dados em painel}

Conforme o exposto na subseção 4.1, os Modelos de regressão com dados em painel foram testados tanto por efeitos fixos, quanto por aleatórios. Os resultados serão demostrados nas Tabelas 4, 5 e 6, de maneira resumida com as variáveis independentes e de controle.

A seguir a Tabela 4 apresenta os resultados obtidos por meio da regressão com dados em painel tanto por efeitos fixos, quanto por aleatórios, para a variável independente tempestividade relacionada com a defasagem na divulgação dos relatórios financeiros e suas respectivas informações.

\begin{tabular}{|c|c|c|}
\hline Variáveis & Modelo 1 (DP1) & Modelo 2 (DP2) \\
\hline \multirow{2}{*}{ Constante } & 0,359763 & 0,197766 \\
\hline & $(0,0001) * * *$ & $(0,0001) * * *$ \\
\hline \multirow{2}{*}{ DP } & 0,000253706 & $5,40014 \mathrm{e}-05$ \\
\hline & $(0,0474)^{* *}$ & $(0,0805)$ * \\
\hline \multirow{2}{*}{ TAM } & $-0,0360287$ & $-0,0150614$ \\
\hline & $(0,0001) * * *$ & $(0,0001) * * *$ \\
\hline \multirow{2}{*}{ END } & 0,0446614 & 0,0313674 \\
\hline & $(0,0005) * * *$ & $(0,0028) * * *$ \\
\hline \multirow{2}{*}{ AUD } & 0,00409222 & $-0,00451055$ \\
\hline & $(0,4198)$ & $(0,3026)$ \\
\hline \multirow{2}{*}{ GOV } & - & 0,00434986 \\
\hline & - & $(0,4029)$ \\
\hline \multirow{2}{*}{ PREJ } & 0,00370163 & 0,0138929 \\
\hline & $(0,3615)$ & $(0,0001) * * *$ \\
\hline \multirow{2}{*}{ CFO } & 0,000887563 & $-0,000925361$ \\
\hline & $(0,5168)$ & $(0,4837)$ \\
\hline R2 & 0,381067 & 0,113803 \\
\hline
\end{tabular}




\begin{tabular}{|c|c|c|}
\hline $\mathrm{N}$ & 1548 & 1548 \\
\hline Efeito do Painel & Fixo & Aleatório \\
\hline \multicolumn{3}{|c|}{$\begin{array}{l}\text { DP = Dias de publiçação; DP1 = Dias de Publicação da Primeira Versão; DP2= Dia } \\
\text { de Publicação da Ulltima Versão; TAM = Tamanho da Empresa; AUD = Empresa } \\
\text { Auditadas pela Big Four, END = Nivel de Endividamento; GOV = Níveis de Governanç } \\
\text { Corporativa; PREJ = Empresas que apresentaram Prejuízo; FCO = Fluxo Operaciona } \\
\text { de Caixa das Empresas. }\end{array}$} \\
\hline
\end{tabular}

Nota. Os valores constantes fora dos parênteses representam os coeficientes da regressão, os valores dentro dos parênteses representam op-valor $e^{* * *},{ }^{* *} e^{*}$ correspondem à significância estatística nos níveis de 1\%, 5\% e 10\%, respectivamente. Fonte: Resultados da pesquisa (2020).

A Tabela 4 evidenciou que, no Modelo 1, a variável independente DP1 possui relação positiva e com o nível de significância de $5 \%$ com a variável dependente ADD. As variáveis de controle AUD, PREJ e FCO apresentam relação positiva com a variável dependente $A D D$, porém, nenhuma destas variáveis apresentaram resultado significativo. A variável TAM e END apresentaram relação significativa ao nível de $1 \%$ com a variável dependente ADD, porém, TAM apresentou relação negativa enquanto que END apresentou relação positiva.

Enquanto que no Modelo 2 a variável independente DP2 também possui relação positiva e significativa ao nível de $10 \%$ com a variável dependente ADD. As variáveis TAM, AUD e FCO apresentam relação negativa e somente TAM tem relação significativa com nível de $1 \%$ com a variável dependente ADD. Já as variáveis END, GOV e PREJ apresentam relação positiva, mas somente END e PREJ possuem relação significativa ao nível de $1 \%$ com a variável dependente ADD.

A seguir a Tabela 5 apresenta os resultados obtidos por meio da regressão com dados em painel tanto por efeitos fixos, quanto por aleatórios, para a variável independente tempestividade relacionada com a perda do prazo da divulgação dos relatórios financeiros e suas respectivas informações.

Tabela 5 - Relações entre Perda do Prazo com Gerenciamento de Resultados

\begin{tabular}{|c|c|c|c|}
\hline Variáveis & $\begin{array}{l}\text { Modelo } 3 \\
\text { (PDDFP) }\end{array}$ & $\begin{array}{l}\text { Modelo } 4 \\
\text { (PDITR) }\end{array}$ & $\begin{array}{c}\text { Modelo } 5 \\
\text { (PDDFPITR) }\end{array}$ \\
\hline \multirow{2}{*}{ Constante } & 0,381661 & 0,385563 & 0,196907 \\
\hline & $(0,0001) * * *$ & $(0,0001) * * *$ & $(0,0001) * * *$ \\
\hline \multirow{2}{*}{ PD } & 0,0402124 & 0,00785173 & 0,0370760 \\
\hline & $(0,0199)^{* *}$ & $(0,7201)$ & $(0,0655) *$ \\
\hline \multirow{2}{*}{ TAM } & $-0,0365166$ & $-0,0368042$ & $-0,0149074$ \\
\hline & $(0,0001)^{* * *}$ & $(0,0001)^{* * *}$ & $(0,0001)^{* * *}$ \\
\hline \multirow{2}{*}{ END } & 0,0458846 & 0,0460478 & 0,0301602 \\
\hline & $(0,0004) * * *$ & $(0,0003)^{* * *}$ & $(0,0044)^{* * *}$ \\
\hline \multirow{2}{*}{ AUD } & 0,00445547 & 0,00449811 & $-0,00421151$ \\
\hline & $(0,3848)$ & $(0,3815)$ & $(0,3361)$ \\
\hline \multirow{2}{*}{ GOV } & \multirow{2}{*}{-} & \multirow{2}{*}{ - } & 0,00494845 \\
\hline & & & $(0,3341)$ \\
\hline \multirow{2}{*}{ PREJ } & 0,00454338 & 0,00492388 & 0,0135532 \\
\hline & $(0,2610)$ & $(0,2224)$ & $(0,0001) * * *$ \\
\hline \multirow{2}{*}{ CFO } & 0,000917994 & 0,000748702 & $-0,000839763$ \\
\hline & $(0,5043)$ & $(0,5879)$ & $(0,5243)$ \\
\hline R2 & 0,381568 & 0,379338 & 0,120886 \\
\hline $\mathrm{N}$ & 1548 & 1548 & 1548 \\
\hline Efeito do Painel & Fixo & Fixo & Aleatório \\
\hline
\end{tabular}

Nota. Os valores constantes fora dos parênteses representam os coeficientes da regressão, os valores dentro dos parênteses representam o p-valor $e^{* * *},{ }^{* *} e^{*}$ correspondem à significância estatística nos níveis de 1\%, 5\% e 10\%, respectivamente.

Fonte: Resultados da pesquisa (2020). 
A Tabela 5 evidenciou que nos Modelos 3 e 5 a variável independente PD possui relação positiva e significativa com a variável dependente ADD, enquanto no Modelo 4 não apresentou resultado significativo apenas indicando que as variáveis ADD e PDITR possuem relação positiva entre si. Sendo que os Modelos 3 e 5 apresentaram nível de significância de 5\% e 10\%, respectivamente. A variável TAM, nos três Modelos, apresentou relação negativa e significativa ao nível de $1 \%$ com a variável dependente ADD. A variável END, nos três Modelos, apresentou que está associada positivamente com a variável dependente ADD ao nível de 1\% de significância. No Modelo 3, 4 e 5 as variáveis AUD, PREJ e FCO apresentaram relação positiva, porém, somente no Modelo 5 a variável PREJ apresentou nível de significância de $1 \%$ com a variável dependente ADD, as demais não apresentaram nível de significância. Somente, no Modelo 5, a variável GOV apresentou resultado indicando que está associada positivamente a variável dependente ADD, mas que não apresentou suporte estatísticos.

A seguir a Tabela 6 apresenta os resultados obtidos por meio da regressão com dados em painel por efeitos fixos para a variável independente tempestividade relacionada com a republicação dos relatórios financeiros e suas respectivas informações.

Tabela 6 - Relações entre Republicação com Gerenciamento de Resultados

\begin{tabular}{|c|c|c|c|}
\hline Variáveis & Coeficientes & P-Valor & Significância \\
\hline Constante & 0,376564 & 0,0001 & $* * *$ \\
\hline REP & 0,00523659 & 0,0896 & * \\
\hline TAM & $-0,0359874$ & 0,0001 & $* * *$ \\
\hline END & 0,0463787 & 0,0003 & $* * *$ \\
\hline AUD & 0,00389714 & 0,4510 & \\
\hline GOV & - & - & \\
\hline PREJ & 0,00506841 & 0,2054 & \\
\hline CFO & 0,000740921 & 0,5890 & \\
\hline R2 & 0,380698 & & \\
\hline $\mathrm{N}$ & 1548 & & \\
\hline Efeito do Painel & Fixo & & \\
\hline $\begin{array}{l}\mathrm{REP}=\text { Republicaçãa } \\
\text { Endividamento; } \mathrm{G}\end{array}$ & $\begin{array}{l}\text { nanho da Emp } \\
\text { de Governança } \\
\text { ício; FCO= Flux }\end{array}$ & $\begin{array}{l}\text { esas Audi } \\
\text { EJ=Empr } \\
\text { Caixa das }\end{array}$ & $\begin{array}{l}u r, \text { END }=\text { Nível } \\
\text { aram Prejuízo }\end{array}$ \\
\hline
\end{tabular}

Nota. ${ }^{* * *},{ }^{* *} e^{*}$ correspondem à significância estatística nos níveis de 1\%, 5\% e 10\%, respectivamente. Fonte: Resultados da pesquisa (2020).

A Tabela 6 corresponde aos resultados obtidos no Modelo 6 desta pesquisa. Os resultados alcançados evidenciam que todas as variáveis neste modelo apresentaram relação positiva, exceto a variável TAM, com a variável dependente ADD. Sendo que as variáveis AUD, PREJ e CFO não apresentam nível de significância com a variável dependente ADD. Mas as variáveis REP, TAM e END possuem nível de significância de 10\%,1\% e 1\%, respectivamente, com a variável dependente ADD. A variável GOV não apresentou resultado neste modelo.

4.3 Discussão dos resultados

Os Modelos 1 e 2 apresentaram resultados que evidenciam que a defasagem na divulgação tem relação positiva e significativa com o gerenciamento de resultados, ou seja, confirma a hipótese 1 de que quanto maior o número de dias decorridos para a divulgação dos relatorios financeiros tendem a apresentar maior nível de gerenciamento de resultados reportando lucros de baixa qualidade aos usuários da informação.

A literatura menciona que as empresas que apresentam prejuízos tendem a ser aquelas que tardam o momento de divulgação dos relatórios fianceiros como também considera-o como incentivo à prática 
de gerenciamento de resultados, por meio do Modelo 2 apresentou resultado significativo do prejuízo com o gerenciamento de resultados fomentando a relação sugerida pela hipótese 1.

Os achados da hipótese 1 corroboram com os resultados obtidos, referente aos fatores determinantes da defasagem na publicação, dentre eles, o prejuízo, nas pesquisas de Paulo e Leme (2009), Silva et al. (2006) como também nos estudos de Kirch et al. (2012), Barcellos et al. (2014) e Sá (2014) associados aos incentivos para o gerenciamento de resultados, indicados na pesquisa de Paulo (2007).

Os resultados da hipótese 2 apontam que o gerenciamento de resultados está relacionado positiva e significativamente com a perda do prazo dos relatórios financeiros, isto é, as empresas que perdem o prazo de divulgação de seus relatórios, possuem uma maior probabilidade de gerenciar seus resultados.

Estes resultados corroboram com os achados obtidos nas pesquisas de Souza et al. (2018) os quais apontam os fatores que influenciam na perda do prazo de divulgação sendo, também, estes fatores considerados como incentivos de gerenciamento de resultados que reportam lucros de baixa qualidade aos usuários, conforme Dechow et al. (2010), Paulo (2007), Martinez (2001) e Martinez (2013).

Os resultados referente a hipótese 3 obtido por meio do sexto Modelo de regressão evidenciou que, de fato, há relação positiva e significativa entre as variáveis, aceitando a hipótese de que as empresas que republicam seus relatorios financeiros tendem a um maior gerenciamento de resultados reportando lucros de menor qualidade aos usuários.

Sendo assim, pode-se afirmar que a republicação pode indicar ação oportunista por parte dos gestores corroborando com os resultados das pesquisas de Dechow et al. (2010) e Marques et al. (2017) que apontam que a republicação tem relação positiva com o gerenciamento de resultados.

Ressalta-se que a presença das variáveis de controle, neste estudo, apoia a explicação do modelo sobre as variações da variável de interesse do estudo, neste caso, o gerenciamento de resultados por meio dos accruals discricionários, pois quanto mais variáveis explicativas existentes no modelo de regressão com dados em painel melhor será poder de explicação do mesmo.

Os resultados encontrados nesta pesquisa denotam que empresas que não são tempestivas na divulgação dos relatórios financeiros são propensas a ação oportunista mediante de gerenciamento de resultados reportando lucros de baixa qualidade aos usuários da informação, visto que, segundo Cupertino (2013), o período de divulgação é propício para esta ação oportunista dos gestores que pela flexibilização da regulamentação e os padrões contábeis possibilita a discricionariedade dos gestores na tomada de decisão (Goulart, 2007).

\section{CONSIDERAÇÕES FINAIS}

Este estudo teve como intuito verificar o efeito da tempestividade dos relatórios financeiros na qualidade dos lucros reportados mediante gerenciamento de resultados pelas empresas brasileiras de capital aberto listadas na B3. Para isso foram utilizadas 172 empresas entre o período de 2010 a 2018, sendo, 1548 observações utilizadas neste período.

Estudos anteriores apresentam como proxies de tempestividade a defasagem, a perda do prazo de divulgação e a republicação dos relatórios financeiros. Neste estudo, utilizaram-se essas proxies de tempestividade para relaciona-las com a prática do gerenciamento de resultados.

Nesta pesquisa, a proxy de gerenciamento de resultados foi constituída pelos accruals discricionários mediante o modelo de gerenciamento de Jones Modificado por Dechow et al. (1995). Esta foi determinada 
como a variável de interesse de estudo, e foram delineados seis modelos de regressão relacionados com a variável explicada, sendo cada modelo relacionado a uma proxy de tempestividade distinta.

Nos seis modelos estimados foram inseridas variáveis de controle com a finalidade de melhor explicar as variações da variável de interesse desta pesquisa. Sendo elas:Tamanho (TAM), Nível de Endividamento (END), Empresas Auditadas por Big Four (AUD), Nível de Governança Corporativa (GOV), Prejuízo (PREJ) e Fluxo de Caixa Operacional (CFO).

Nos modelos referente a primeira hipótese, os achados evidenciaram que a defasagem da divulgação está associada positiva e significativamente com a prática de gerenciamento de resultados, ou seja, empresas que têm um prazo maior de divulgação, possui alto nível de accruals discricionários, o que indica a presença de gerenciamento de resultados reportando lucros de baixa qualidade aos usuários da informação.

Nos modelos que referem-se à segunda hipótese, sobre a perda do prazo de divulgação dos relatórios financeiros, observa-se que o gerenciamento de resultados está relacionado positivamente e significativamente com a perda do prazo, o que significa que as empresas que tendem a perder o prazo de divulgação de seus relatórios tendem apresentar resultados gerenciados reportando lucros de baixa qualidade aos usuários.

No modelo relacionado a republicação dos relatórios financeiros, referente a terceira hipótese, os resultados apresentaram que a republicação dos relatórios financeiros possui relação positiva e significativa com o gerenciamento de resultados, sendo assim, pode-se afirmar que a republicação é indicativo da presença de ação oportunista por parte dos gestores. Resultado obtido reforça as evidências da literatura quanto investigação da relação entre as duas ações dos gestores.

Por fim, os achados desta pesquisa fornecem evidências de que a tempestividade dos relatórios financeiros tem efeito positivo e significativo na baixa qualidade dos lucros reportados pelas empresas de companhia aberta mediante gerenciamento de resultados. Assim, corroboram-se com as pesquisas de Healy e Whalen (1999) e Schipper (1989) os quais apontam que a presença de gerenciamento de resultados indica que houve intervenção proposital no processo de divulgação dos relatórios financeiros os quais não fornecem informação sobre a real situação econômico-financeira da empresa, mas aquela de interesse dos gestores.

O estudo limita-se pela utilização de apenas um modelo de gerenciamento de resultados, já bastante utilizado pelo arcabouço teórico sobre gerenciamento de resultados contábeis no Brasil. Porém esta utilização justifica-se pela aceitabilidade deste modelo pela academia brasileira apontando como um dos mais adequados para as empresas brasileiras.

Sugere-se ainda que, para pesquisas futuras, possam ser feito análise de dados por meio dos accruals discricionários mediante a utilização de outros modelos de gerenciamento de resultados, bem como a utilização de outras proxies de qualidade dos lucros que não sejam, necessariamente, referente ao oportunismo da gestão perante os dados contábeis.

Ahmad, R. A. R., \& Kamarudin, K. (2003). Audit delay and the timeliness of corporate reporting: Malaysian evidence. In: Hawaii International Conference on Business, 3. 
Almeida, J. E. F., \& Almeida, J. C. G. (2009). Auditoria e earnings management: estudo empírico nas empresas abertas auditadas pelos big four e demais firmas de auditoria. Revista Contabilidade \& Finanças, 20(50), 62-74. https://doi.org/10.1590/S1519-70772009000200005

Baptista, E. (2009) Teoria em gerenciamento de resultados. Revista de Contabilidade da UFBA, 3(2), 5-20.

Barcellos, L. P., Costa Júnior, J. V., \& Laurence, L. C. (2014). Determinantes do Prazo de Divulgação das Demonstrações Contábeis das Companhias Não Financeiras Listadas na Bovespa. Revista de Contabilidade e Organizações, 20(8). https://doi.org/10.11606/rco.v8i20.69265

Costa, A. C. O., Teixeira, A. J. C., \& Nossa, V. (2002). Conservadorismo, accruals e qualidade dos lucros contábeis. XXVI ENANPAD, Salvador, BA, Brasil.

CPC 00 (R2). Estrutura Conceitual para Elaboração e Divulgação de Relatório Contábil-Financeiro. Brasília. 2019. Recuperado em 09 de julho, 2019, de http://static.cpc.aatb.com.br/Documentos/573_CPC00(R2).pdf

Cupertino, C. M. (2013). Gerenciamento de resultados por decisões operacionais no mercado de capitais brasileiro. Tese de Doutorado, Universidade Federal de Santa Catarina, Florianópolis, SC, Brasil. https:// repositorio.ufsc.br/xmlui/handle/123456789/122592

Dechow, P. M., Sloan, R. G., \& Sweeney, A. P. (1995). Detecting earnings management. Accounting Review, 193-225. https://www.jstor.org/stable/248303

Dechow, P., Ge, W., \& Schrand, C. (2010). Understanding earnings quality: A review of the proxies, their determinants and their consequences. Journal of Accounting and Economics, 50(2-3), 344-401. https:// doi.org/10.1016/j.jacceco.2010.09.001

Di Pietra, R., Mcleay, S. \& Ronen, J. (2014). Accounting and Regulation: new insigths on Governance, Markets and Institutions. New York: Springer.

Goulart, A. M. C. (2007). Gerenciamento de resultados contábeis em instituições financeiras no Brasil. Tese de Doutorado, Universidade de São Paulo, São Paulo, SP, Brasil.

Healy, P. M., \& Wahlen, J. M. (1999). A review of the earnings management literature and its implications for standard setting. Accounting Horizons, 13(4), 365-383. https://doi.org/10.2308/acch.1999.13.4.365

Hendriksen, E. S., \& Van Breda, M. F. (2012). Teoria da contabilidade. (5a. ed.) São Paulo: Atlas.

Jensen, M. C., \& Meckling, W. H. (1976). Theory of the firm: Managerial behavior, agency costs and ownership structure. Journal of financial economics, 3(4), 305-360. https://doi.org/10.1016/0304-405X(76)90026-X

Kirch, G., Lima, J. B., \& Terra, P. R. S. (2012). Determinants of disclosure timing for financial statements of Brazilian public companies. Revista Contabilidade e Finanças, 23(60), 173-186. https://doi.org/10.1590/ S1519-70772012000300003

Lei n. 6.404, de 15 de dezembro de 1976. Dispõe sobre as sociedades por ações. Recuperado de http:// www.planalto.gov.br/ccivil03/LEIS/L6404consol.htm

Lei n. 11.638, de 28 de setembro de 2007. Altera e revoga dispositivos da Lei n. 6.404, de 15 de dezembro de 1976, e da Lei n. 6.385, de 7 de dezembro de 1976, e estende às sociedades de grande porte disposições relativas à elaboração e divulgação de demonstrações financeiras. Recuperado de https://www. planalto.gov.br/ccivil03/ato2007-2010/2007/lei//11638.htm

Marques, V. (2016). Qualidade das Informações Financeiras e o Ambiente Regulatório: Evidências Empíricas no Período de 1998-2013. Tese de Doutorado, Universidade Federal de Minas Gerais, Belo Horizonte, MG, Brasil.

Marques, V. A., Amaral, H. F., de Souza, A. A., dos Santos, K. L., \& Belo, P. H. R. (2017). Determinantes das Republicações no Mercado Brasileiro: Uma Análise a partir dos Incentivos ao Gerenciamento de Resultados. Revista de Educação e Pesquisa em Contabilidade (REPeC), 11(2), 187-209. https://doi.org/10.17524/ repec.v11i2.1488 
Martinez, A. L. (1998). Agency theory na pesquisa contábil. XXII ENANPAD, Foz do Iguaçu, PR, Brasil.

Martinez, A. L. (2001). "Gerenciamento" dos Resultados Contábeis: Estudo Empírico das Companhias Abertas Brasileiras. Tese de Doutorado, Universidade de São Paulo, São Paulo, SP, Brasil. https://10.11606/T.12.2002.tde-14052002-110538

Martinez, A. L., \& Cardoso, R. L. (2009). Gerenciamento da informação contábil no Brasil mediante decisões operacionais. Revista Eletrônica de Administração, 15(3), 1-27.

Martinez, A. L. (2011). Do corporate governance special listing segments and auditing curb real earnings management and accrual-based earnings management? Evidence from Brazil. Revista Universo Contábil, 7(4), 98-117. https://doi.org/10.4270/RUC.2011433

Martinez, A. L. (2013). Gerenciamento de resultados no Brasil: um survey da literatura. BBR-Brazilian Business Review, 10(4), 1-31.

Milgrom, P., \& Roberts, J. (1992). Economics, Organizacional \& Management. New Jersey: Prentice-Hall.

Moreira, A.T., Jones, G. D. C., Tavares, M., Fehr, L. C. F. D. A., \& Silva Filho, O. A. D. (2014). Um estudo comparativo do EBITDA e do Fluxo de Caixa Operacional em empresas brasileiras do setor de Telecomunicações. Revista de Gestão, Finanças e Contabilidade, 4(3), 05-22.

Nascimento, A. M., \& Reginato, L. (2008). Divulgação da informação contábil, governança corporativa e controle organizacional: uma relação necessária. Revista Universo Contábil, 4(3), 25-47. https://dx.doi. org/10.4270/ruc.20084

Owusu-Ansah, S., \& Leventis, S. (2006). Timeliness of corporate annual financial reporting in Greece. European Accounting Review, 15(2), 273-287. https://doi.org/10.1080/09638180500252078

Paulo, E. (2007). Manipulação das informações contábeis: uma análise teórica e empírica sobre os modelos operacionais de detecção de gerenciamento de resultados. Tese de Doutorado, Universidade de São Paulo, São Paulo, SP, Brasil. https://doi.org/10.11606/T.12.2007.tde-28012008-113439

Paulo, E. P., \& Leme, J. R. (2009). Gerenciamento de resultados contábeis e o anúncio dos resultados contábeis pelas companhias abertas brasileiras. Revista Universo Contábil, 5(4), 27-43. https://dx.doi. org/10.4270/ruc.20095

Sá, T. S. (2014). Tempestividade da informação: uma análise dos fatores que influenciam o prazo de publicação das demonstrações financeiras no Brasil. Dissertação de Mestrado, Universidade de Brasília, Brasília, DF, Brasil. https://dx.doi.org/10.26512/2014.12.D.17842

Schipper, K. (1989). Earnings management. Accounting Horizons, 3(4), 91-102.

Silva, C. E. V., Silva, A. H. C., \& Sancovschi, M. (2006) Evidências sobre o prazo médio de publicação de demonstrações contábeis de empresas brasileiras de capital aberto. VI Congresso USP de Controladoria e Contabilidade, São Paulo, SP, Brasil.

Souza, P. V. S., Silva, A. G. A., \& Macedo, M. A. S. (2018). Determinantes da perda do prazo de divulgação dos relatórios financeiros das companhias brasileiras de capital aberto. Revista Contemporânea de Contabilidade, 15(37), 52-70. https://doi.org/10.5007/2175-8069.2018v15n37p52

Subramanyam, K. R. (1996). The pricing of discretionary accruals. Journal of accounting and economics, 22(1-3), 249-281. https://doi.org/10.1016/S0165-4101(96)00434-X

Türel, A. G. (2010). Timeliness of financial reporting in emerging capital markets: Evidence from Turkey. European Financial and Accounting Journal, 5(3-4), 113-133. https://dx.doi.org/10.18267/j.efaj.58 